\title{
ANALYSIS AND IMPLEMENTATION OF UBUNTU AND MIKROTIK BASED SERVER
}

\author{
Januardi Nasir
}

\begin{abstract}
Internet is a primary requirement in this modern era because it is one of the information's media and communication. Due to its rapid advancement, internet is now a main infrastructure which must be possessed by an organization, institution (education, government, service provider and others). Besides internet, other infrastructure which is also a primary requirement in an institution is a centralized storage or server. Regarding internet's availability and server, PT Indonesia Terbit Media faces some setbacks such as the unavailability of sufficient bandwidth management and unavailability of centralized information storage. To solve those setbacks, a MikroTik router is offered to be implemented in the company's network. Before doing research, observation is held in the company to gather information's regarding current network. Along with observation, focus group discussion is held with the staffs. After information's are gathered, current network is analyzed then a new topology is proposed. After the proposal is approved, testing phase is initiated to know the contributions of newly proposed network in solving the mentioned setbacks. Results from the implementation are such as bandwidth management is applied in new network which is resulting in stable internet's speed even though a user is downloading a quite large file and Ubuntu-based centralized server.

Keywords: internet ; server ; ubuntu ; MikroTik ; bandwidth management
\end{abstract}

\section{INTRODUCTION}

Batam is one of the industrial cities, which needs fast and accurate information. PT Indonesia Terbit Media is one of the companies, which is engaged in journalism and provides information about Batam and it is served in the format of a website[1]. Fast internet connection is required to support those necessities. Besides the internet, other infrastructure, which is the main requirement in a company, is a centralized storage or usually called as server.[2] A large scaled company or business entity usually use a physical server as its centralized storage[3]. Whereas for the small to intermediate-scaled company mostly uses PC as the centralized storage because it is fairly cheaper than the physical server (which is usually more expensive).[4] Server is usually used by the staff or workers to keep important information related to company's privacy such as data, transaction and others[5]. Each staff or worker is usually given permission according to their own department so no one from certain department can get an access through other department's data.[6] The operating system, which is commonly used by server, is Windows because it is easy to operate. There are few servers, which uses Linux as their operating system because it is more secure.[7]

\section{RESEARCH METHOD}

\section{1) Current Network Topology}

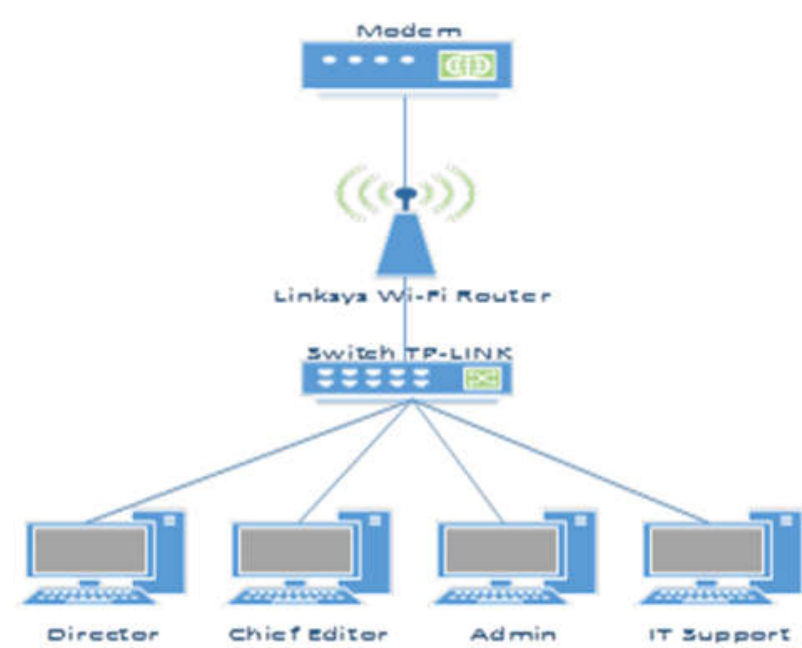

Figure. 1 Current Network Topology

Star topology is currently being used in the company's network. End devices consist of four laptop computers which are used respectively by director, chief editor, admin and IT support and all. Linksys Wi-Fi router is being used as wireless device with WAP/PSK authentication.[8]

2) Proposed Network Topology
Januardi Nasir are with the Department of.Technique, Universiti Putera Batam, Batam, Indonesia (email : januardinasir@gmail.com) 


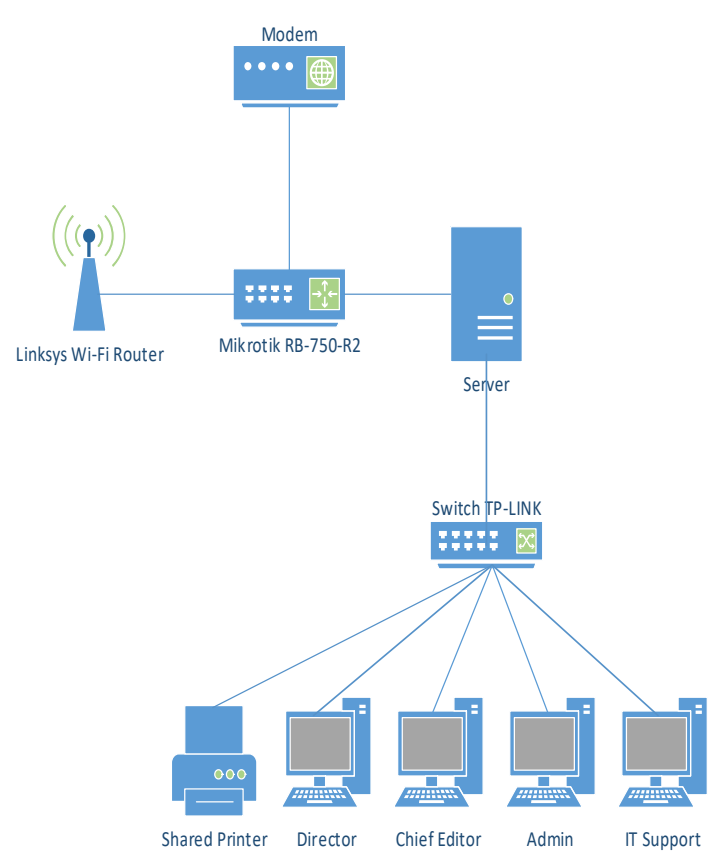

Figure 2 Proposed Network Topology

3) . MikroTik RB-750-R2 router is directly connected to modem (internet connection from ISP)[9]. Wi-Fi router and server are connected to MikroTik router where bandwidth management will be implemented for both local network and wireless network[10]. Local network consists of four laptop computers and a shared printer which are connected to a TP-LINK switch.

\section{RESUlTS AND ANALYSIS}

\section{1) $\mathrm{SSH}$ (Secure Shell)}

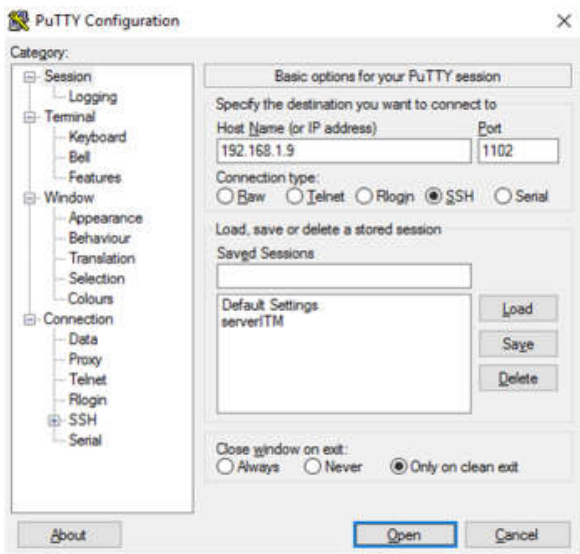

Figure 3 Remote login to server using PuTTY

Figure 3 shown above is the initial display when PuTTY is opened. In Host Name or IP Address section, type the desired server's IP address and the port number. Choose SSH in Connection type and press enter[11].

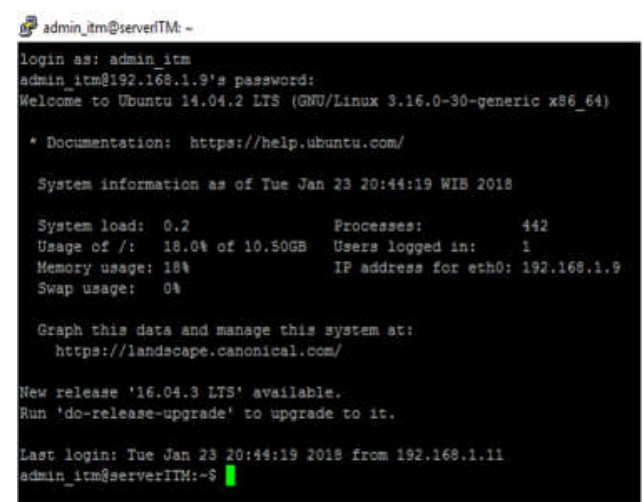

Figure 4 Remote login to server established

Figure 4 shown above is PuTTY's display when the remote login has been established and now the server can be accessed remotely from a client's computer.[12]

2) Mail Server

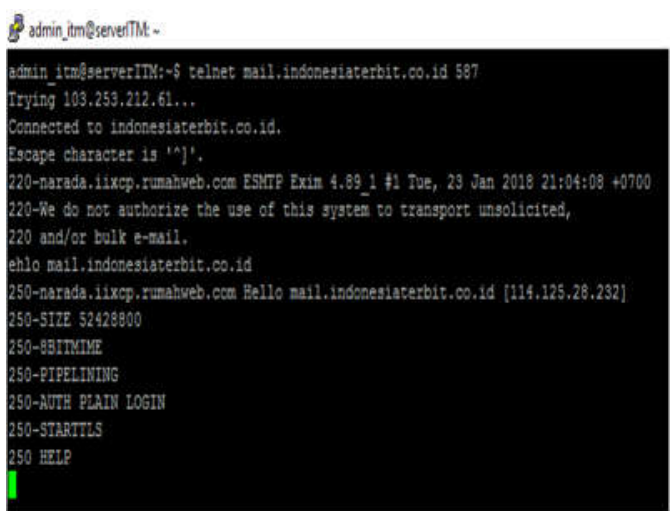

Figure 5 Testing web server using wget command

Wget command is used to send request to webpage of www.indonesiaterbit.co.id and after a few seconds, the request is accepted or responded by the web page.[13]

3) Web Server

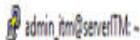

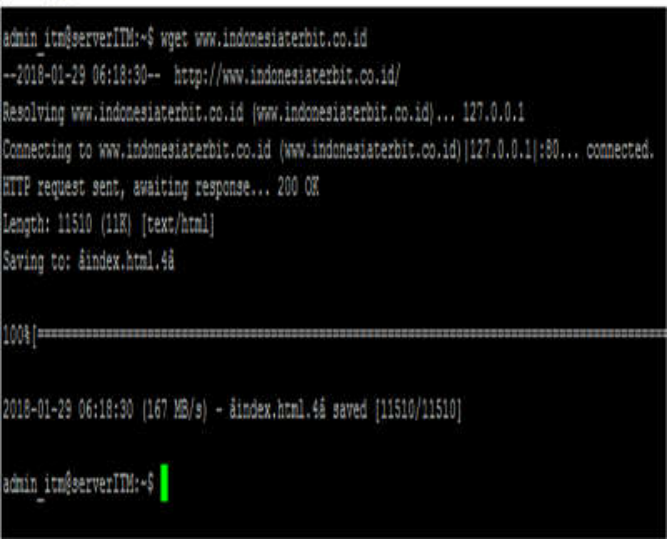

Figure 6 Testing web server using wget command 
Wget command is used to send request to webpage of www.indonesiaterbit.co.id and after a few seconds, the request is accepted or responded by the web page.[14]

\section{4) DNS Server}

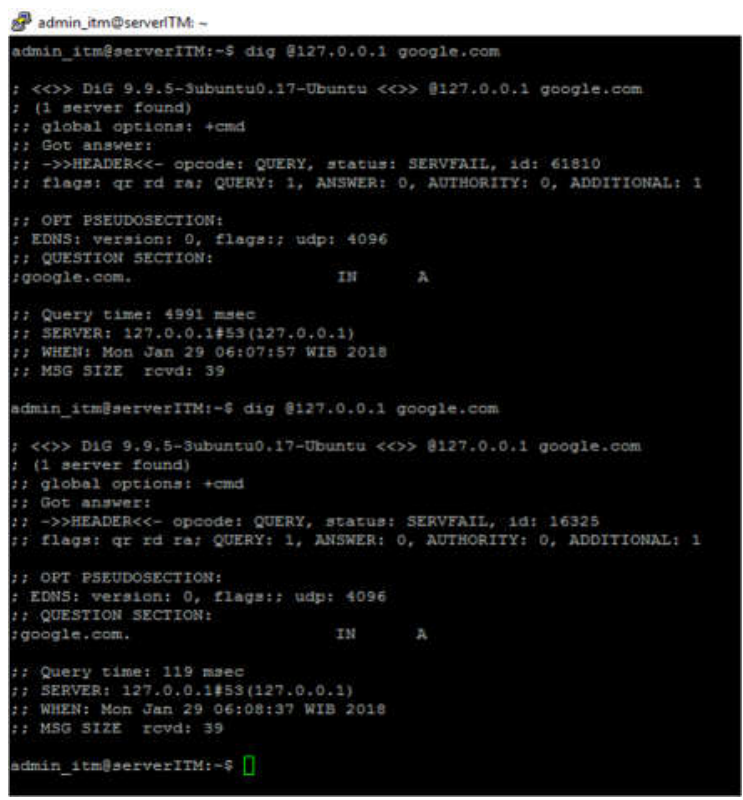

Figure 7 Testing DNS server using dig command

Dig command is used to check the query time of a certain domain. For the first dig, the query time is 4991 msec. After trying the second dig, the query time is increasing to $119 \mathrm{msec}$.

\section{5) MikroTik-based Bandwidth Managemen}

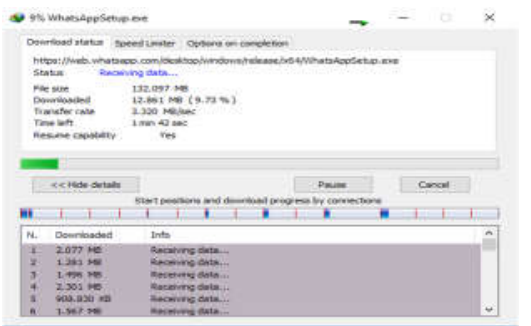

Figure 8 Download speed before bandwidth management

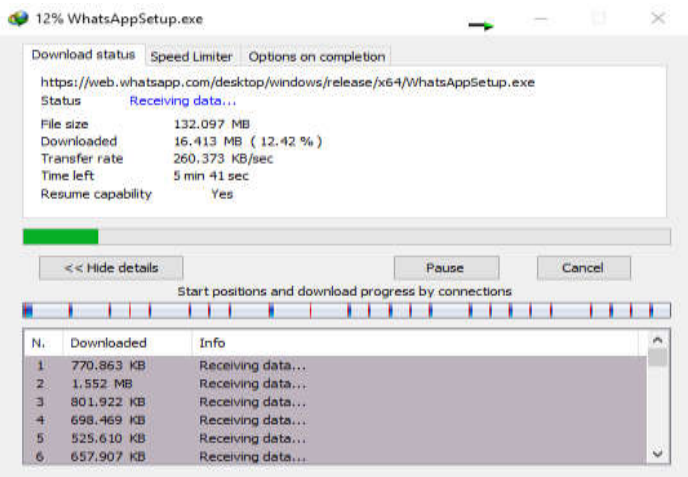

Figure 9 Download speed after bandwidth management
Figure 9 above shows the download speed using Internet Download Manager is reaching up to $3 \mathrm{Mbps}$ which causes this situation to slow down the browsing, streaming, upload and download process in other devices[15]. But after bandwidth management is implemented, download speed is limited up to $260 \mathrm{kbps}$ as shown in figure 14, resulting in other devices are not experiencing excessive delay during browsing, streaming, upload and download.

\section{CONCLUSIONS}

Implementation of Ubuntu as a centralized storage or server succeed and works like it supposed to be and MikroTik-based bandwidth management with queue tree method effectively increases the quality of service in network's traffic by limiting bandwidth for each device within the network.

\section{REFERENCES}

[1] H. S. Oluwatosin, "Client-Server Model," IOSR J. Comput. Eng., vol. 16, no. 1, pp. 57-71, 2014.

[2] A. L. I. A. A. RAMADHAN et al., "Analysis of Effectiveness of Using Simple Queue With Per Connection Queue (Pcq) in the Bandwidth Management (a Case Study At the Academy of Information Management and Computer Mataram (Amikom) Mataram)," Journal of Theoretical and Applied Information Technology, vol. 83, no. 3. 2016.

[3] A. Rahman and Haviluddin, "Implementation of Bandwidth Management Authentication," Int. J. Comput. Informatics, vol. 1, no. 1, pp. 1-8, 2016.

[4] P. Mollick, S. Biswas, A. Halder, and M. R. Salmani, "Mikrotik Router Configuration using IPv6," Int. J. Innov. Res. Comput. Commun. Eng., vol. 4, no. 2, pp. 2001-2007, 2016.

[5] I. Perwira and Liantoni, "Queue Tree Implementation for Bandwidth Management in Modern Campus Network Architecture," vol. 3, no. 1, pp. 17-26, 2018.

[6] W. Von Hagen, Ubuntu 8.10 Linux ${ }^{\circledR}{ }^{\circledR}$. Indianapolis: Wiley Publishing, Inc., 2009.

[7] W. Sugeng, J. E. Istiyanto, K. Mustofa, and A. Ashari, "The Impact of QoS Changes towards Network Performance," Int. J. Comput. Networks Commun. Secur., vol. 3, no. 2, pp. 48-53, 2015.

[8] W. Stallings, Network Security Essentials : Applications and Standards Fourth Edition, 4th (Fourt. Upper Saddle River, New Jearsey: Pearson Education, Inc., 2011.

[9] A. Lockhart, Network Security Hacks, Second Edition, Second Edi. California: O’Reilly Media, Inc., 2009.

[10] D. J. Barrett, R. E. Silverman, and R. G. Byrnes, SSH The Secure Shell, Second Edi. California: O'Reilly Media, Inc., 2005

[11] H. Hours, E. Biersack, P. Loiseau, A. Finamore, and M. Mellia, "A Study of the Impact of DNS Resolvers on CDN Performance Using a Causal Approach," Comput. Networks, vol. 109, pp. 200-210, 2016.

[12] W. Stallings, Data and Computer Communications (Eighth Edition). New Jersey: Pearson Education, Inc., 2007.

[13] M. D. L. Siahaan, M. S. Panjaitan, and A. P. U. Siahaan, "MikroTik Bandwidth Management to Gain the Users Prosperity Prevalent," Int. J. Eng. Trends Technol., vol. 42, no. 5, pp. 218-222, 2016. 
[14] V. Negi et al., "Network Security in Embedded System Using TLS," Int. J. Secur. its Appl., vol. 10, no. 2, pp. 375384, 2016.

[15] M. A. Zulkifli and U. A. Dahlan, "Live Forensics Method for Analysis Denial of Service ( DOS ) Attack on Routerboard," Int. J. Comput. Appl., vol. 180, no. 35, pp. 23-30, 2018 